\title{
Accountancy in het digitale landschap
}

Luc van Zutphen

De ontwikkelingen in de wereld van de informatietechnologie (IT) blijven ons boeien en uitdagen. De laatste tijd staat vorral Internet volop in de belangstelling.

Internet is in! Bijna dagelijks is er wel nieuw's over dit wereldwijde netwerk in dagbladen, magazines en via radio en $T V$.

Is hier sprake ran een nieuwe hype in medialand of beleven we de eerste fase van een nieuwe doorbraak in de wereld van informatisering en telecommunicatie? Er hestaat weinig twijfel dat dit laatste ook werkelijk het geval is.

Het aantal aansluitingen op Internet blifft exponenticel groeien. Recente schattingen komen uit op 50 tot 60 miljoen gehruikers, waarvan het merendeel in de Verenigde Staten. Internet is daarmee veruit het grootste conmunicatienetwerk in de wereld. Als netwerken een dergelijke omvang aannemen krijgen ook activiteiten als het vergaren en uitwisselen van kennis en informatie cen totaal andere dimensie.

Het World Wide Web bijvoorheeld kan ook u, lezer achter uw eenvoudige $P C$ - echter wel voorzien van een relatief snel modem (bij voorkeur 28,8 K hps) - van een ongekende mix aan informatie vorzien. Zowel in de vorm van tekst, plaatjes, gehid als (bewegend) beeld. Informatie die met elektronisch gemak kan worden opgehaald van de uitersten der aarde.

Tot voor kort bepaalden de ons ter plaatse ter beschikking staande fysieke informatiedragers

Prof. L.C. van Zutphen is emeritus hoogleraar Accountantscontrole aan de Vrije Universiteit te Amsterdam. Daarnaast is hij voorzitter van het Examenbureau Registeraccountants en lid van de Orde van Organisatiedeskundigen en -Adviseurs. als cassettes, diskettes, boeken en-voor de meer geavanceerden onder ons ook CD-roms - onze persoonlijke informatievoorziening.

Internet neemt deze fysieke begrenzing echter weg. Maar daramee zijn de toekomstige mogelijkheden bij lange na nog niet aangegeven. Volgens velen zullen er ook digitale markten ontstaan die bedrijien in staat stellen hun afnemers op wereldwijde schaal hun produkten en diensten aan te bieden en transacties af te sluiten. Er zijn nut al bedrijven en zelfs financiële instellingen die uitsluitend op deze digitale markt opereren en alleen via een aansluiting op Internet benaderd kunnen worden. Daarbij wordt volledig afstand genomen van de traditionele vormen van verkoop en verkooporganisatie.

De Internet-editie van de New York Times van 4 maart 1996. (Internetadres http:I/nytimesfar. com/times.pdf) vermeldt zelfs de oprichting van gespecialiseerde advertentiebureaus voor 'Web ads' en 'smart messaging', een aan de weensen en eisen van Internetgebruikers aangepaste vorm ran adverteren.

Een ander voorbeeld, dichter bij huis, is het sedert 1994 bestaande 'The International Accounting Network', waarvan onder meer het Rutgers Accounting Web (RAW) van de gelijknamige State University of New Yersey deel uitmaakt.

RAW is een zogenaamd information retrieval systeem, bereikbaar via Internet (adres http:/ nww.rutgers.edulaccounting). Het systeen is bestemd voor opleiders, studenten en praktijkmensen en bevat een schat aan informatie op ons rakgebied.

RAW bevat documentatiematerical dat is ontwikkeld door de aangesloten instellingen van hoger onderwijs en beroepsorganisaties. waar- 
ran het aantal nog steeds groeionde is.

Dit zogeheten Accomnting Education Change Project wordt gesponsored door de American Accounting Association. Het onderwijs- en onderzocksmaterial dat beschikhaar is in deze datahank betreft onder meer casestudies. le-ingen. syllabi. examens, studierapporten e.d.

Thans nemen een vijftal mniversiteiten en een zevental andere organisaties deel aun het project. watronder her American Institule of Certified Public Accountants, het Institute of Internal Auditors, het Institute of Management Accountants en de Financial Accounting Standards Board. leder ran deze deelnemers heeft zich gecommitteerd an de doelstelling van The International Ac'counting Netw'ork: "to build a truly international resource of accounting and auditing knowledge, to build expertise and sources of information in particular areas and to share this knowledge with the other providers'.

Bij mijn weten participeren tot nut toe slechts een Zweedse en een Finse organisatie in dit project. Wordt het geen tijd dat ook Nederland gaat meesurfen op deze golf".

Zeer belangrijk is de strategische raag hoe de toekomst ran het ac'ountantsberoep door deze nieune wellhast revolutionaire vormen van informatisering en informaticted hologie eruit zal gaan zien.

Voor wat hetreft de exterme verslaglegging ontplooien zich ongekende mogelijkheden.

-As the properties of information contimue to change. so must the accounting profession's model of financial reporting' schreef Dwight Wainman in CA Magazine van augustus 1995.

Een model dat flevihel genoeg is om aun de raak rerschillende eisen en werise'n van de verschillende belanghebbenden te kunnen voldoen. De tijd watrin men met één jaarverslag en één jaarrekening voor alle gebruikers kon rolstaan. lijkt te hebhen afgedaan.

Ook de externe informatieverzorging door bedrijien zal in de nabije toekomst in gedigitaliseerde rorm worden gecreëerd, verzonden en ontrangen. Daarbij kan worden gedacht aun bijworbecld:

- een creatief gebruik ran grafische voorstellingen en andere multimediale mogelijkheden, zouls video en audio. ten einde de toegankelijkheid ran de informatie en de motivatie ran de lezers te vergroten:
- het bedrijf kan in zijn jaurverslag ervoor kiezen bepaalde informatie een bijzonder accent te geven en lezers het gebruik ran bepaalde softwarefaciliteiten aan te bieden. zoals smart agents:

- het system van externe verslaggering zal geintegreerd zijn met het totale bedrijfsinformatiesysteem, watadoor op meer efficiënte wijee en op elk gewenst moment een rapport of combinatie van rapportages kan worden samengesteld.

Bij de huidige vormen van evterne verslaggering moeten beleggers e'n andere gë̈nteressecerden wachten op kwartaal-en jaarciifers om te kumnen vaststellen wat de performance van hun investering is. In de nabije toekomst is het zeer. wel mogelijk dat zij met hepaalde autorisaties en ter heschikking gestelde softuare zelf de databank ran de onderneming kumnen doorzoeken op door hen relerant geachte informatie. Zij bepalen dan zelf de gewenste informatic en de daarbij passende zoekcriteria en het moment van verstrekking.

In het huidige systeem heeft de 'insider" soms meer en betere informatie dan het brede imvesteerderspubliek. Dyamisering van de externe verslaggeving via Internet zon deze ongelijkheid in behandeling wellicht belangrijk kunnen terugdringen.

De produktie en distributie van informatic al voor het grootste deel =ijn geautomatiseerd via servers die alle gekoppeld zijn an het Net. De intermediaire rol ran de accountant tussen het bedrijf als verantwoordingsplichtige en informant en de externe belanghebbenden krijgt daardoor eveneens andere accenten. Om an de verwachtingen ran zijn cliënten en het maatschappelijk verkeer in de 'information age' te kumnen voldoen zullen accountants zich moeten concentreren op de specificke informatiebehoeften ran de verschillende stakeholders en de verdergaande analyse daarvan. De daarroor benodigde accountancy-expertise verschuift naar de kwaliteit ran informatie zoals die door de verschillende gebruikers wordt ervaren.

Ook op het gebied ran de accountantscontrote of ruimer business-assurance zullen we opnieun' veranderingen moeten nastreven. 
Zo zal er een grote hehoefte zijn om bij de verclere withouw ran het Web de betronwbaarheid en controleerbartheid in redelijke mate veilig te stellen. De openheid rem de systemen alsook de complexiteit annex beperkte beheershaarheid maken de risico's wel zeer groot. Voor zorer de problemen al worden onderkend =ijn bepaald nog geen geteste oplossingen voorhanden.

Een gezaghebbend blad als het IS Audit \& Control Journal is pas zeer onlangs begonnen met een special over Imternet. Het ligt in de bedoeling in alle nummers van de jaargang 1990 a an dit onderwerp aundacht te besteden. Dat daidt op een inhaalslag.

De groeiende complexiteit van de systemen en de dauraan verknoopte foutenkansen in de goede werking van de soffware e'n de vergrote fouten-en franderisico's zal de roep om controle en assurance ongetwiifeld sterk doen toenemen. Deze zal zich vooral toespitsen op de andit van systemen die de bits en de bytes genereren e'n distribueren, waaronder begrepen de bruikbasrheid en integriteit van de beschikbare informatie rapportagestructuren. matr in veel mindere mate op de accountantscontrole van het verslag zelf. bijroorbeeld de jaarrekening.

Dit alles zou kumnen betekenen dat jaarrekeningcontroles en accountantsverklaringen bij de juarrekening binnen affienbare tijd tot het rerleden gaun behoren.

Bij dynamische en continuele vormen van rapportering als hiervoor anangeduid zouden ook de kosten van accountantscontrole van histori- sche informatic op een bepaulde peildatum prohibitief kumne'n worden. Het primaire focusobject roor de controlerend acconntant zal in de nabije toekomst het IT-systeem zelf moeten zijn en de organisatio' watain het is ingebed. Betrouwharheid, beveiliging, controleerbatheid. privacy en contimuiteit zijn eigenschappen die ook de moderne en expanderende computernetwerken niet kunne'n ontheren.

Tijdens de bouw van dergelijke systemen kumnen anditors juist ten antien van deze aspecten gericht adviseren e'n een belangrijke rol spelen bij het war borgen van de kwaliteit op alt punt.

Accomtancy in het digitale landschap betekent een nienwe en grote uitdaging roor het internationale accountantsheroep. Willen accountants in de tockomst de rrag nat hun diensten op hetzelfde hoge nivean hamdhaven. dan is het opnieun' doordenken en instrumenteren van de accountantsfinctie in de zich omplooiende informatiemaatschappij een zaak van hoge prioriteit.

\section{I T E R A T U U R}

The New York Times, Internet Edition, Monday March 4. 1996.

Dwight Wainman, Voyage into the Digital Universe. CA Magazine August 1995.

The Internet. Special IS Audit \& Control Journal, Volume I, 1996. 